\title{
Household Expenditures And Direct Medical Costs Among Older Adults In Ghana: Evidence From WHO- SAGE Wave 2
}

\section{Paa-Kwesi Blankson}

Korle Bu Teaching Hospital

Sandra Ama Hewlett

University of Ghana

Thomas Akuetteh Ndanu

University of Ghana

Gyaami Amoah

University of Ghana

Matthew Owusu Boamah

Korle Bu Teaching Hospital

Daniel Tormeti

University of Ghana

Patrick Ampofo

University of Ghana

George Mensah

University of Ghana

Nadia Minicuci

National Research Council, Neuroscience Institute

Paul Kowal

World Health Organization Data, Analytics and Delivery for Impact

Margaret Lartey

University of Ghana

Richard Biritwum

University of Ghana

ALFRED YAWSON ( $\square$ aeyawson@ug.edu.gh )

UNIVERSITY OG GHANA

Research article

Keywords: Direct costs, health expenditures, household expenditures, older adults, Ghana, WHO-SAGE 
Posted Date: June 11th, 2020

DOI: https://doi.org/10.21203/rs.3.rs-18835/v2

License: (c) (i) This work is licensed under a Creative Commons Attribution 4.0 International License. Read Full License 


\section{Abstract}

Background: The Ghanaian population aged 60 years and older will almost double to reach $14 \%$ of the total population by 2050. Ascertaining the pattern of health expenditures among this growing population group is important to inform policy makers about the targets for financial risk protection as part of achieving Universal Health Coverage (UHC) by 2030. This study aimed to estimate household expenditures among older adults and determine their direct medical costs.

Methods: The World Health Organization's Study on global AGEing and adult health (SAGE) Wave 2 was conducted in China, Ghana, India, Mexico, Russian Federation, and South Africa between 2014 and 2015, as a follow-up to Wave 0 in 2003 to 2004 and Wave 1 in 2007 to 2010. Survey questions explored sources of income and total directhousehold expenditures in the year preceding the interview. SAGE Ghana was implemented using face-to-face interviews in a nationally representative sample of persons aged 50+ years with a comparison sample of younger adults aged 18-49 years.

Findings: Analyses included a total of 4,735 participants, with 1,948 (43.8\%) males and 2,787 (56.2\%) females, with a mean age of $57.6( \pm 16.7)$. The average annual household expenditure was US\$2,458 $( \pm 7,374)$. Older adults had higher expenditure levels at US\$2,501 $( \pm 8,307)$, as compared to younger adults, US\$2,309 $( \pm 3,056)$. Direct health-related and food costs accounted for $10 \%$ and $35 \%$ respectively of the total household expenditure. The prevalence of catastrophic health expenditure in households of older adults in Ghana was 7.5\% (95\% Cl 6.0\% - 9.3\%).

Conclusion: These updated estimates on household expenditure among older adults provide needed evidence to support the inclusion of social protection mechanisms in the national ageing agenda. The National Health Insurance reduced the burden of direct health expenditure for households with older adults.

\section{Background}

Like many other countries, Ghana is experiencing a demographic transition charcterised by rapid aging. The population aged 60 years and older in Ghana is currently $5.3 \%$ and is projected to reach $14.1 \%$ of the total population by $2050(1,2)$. The ageing population typically modifies disease burden patterns in countries, with increasing impact of age-related health conditions, while emerging economies like Ghana, in addition, continue to cope with the burden of infectious diseases, injuries and non-communicable diseases (3). It seems however, that many health services may not adequately be prepared for services tailored to the peculiar needs of the elderly (2). Furthermore, older adults in Ghana could often be at higher financial risk of impoverishing health expenditures as a result of often having greater health and long-term care needs compared to younger people.

The introduction of the National Health Insurance Scheme in 2003 has contributed to Ghana's targets to achieve Universal Health Coverage (UHC), although inequalities remain in health service coverage and financial risk protection (4). A National Ageing Policy for Ghana (5) was adopted in 2010, seeking to 
achieve holistic social, economic and cultural re-integration of older people into mainstream society. It also sought to equip them to participate fully in the national development process. Enforcing social protection systems for this population group would be a crucial component of achieving the National Ageing Policy objectives, and would support older Ghanaians to get the health care services they need in the pursuit of Universal Health Coverage (UHC). Despite some comprehensive policies, not much has materialized towards implementing the National Ageing Policy and Implementation Action Plan $(7,8)$

The aging population influences many aspects of society, including economy, labour markets, pensions, taxation, housing demand, and healthcare services $(1,3)$. They are therefore a critical component of the household, which largely remains the unit of production and utilization, especially in emerging economies. Household expenditure analysis is used widely for monitoring general household living standards, wellbeing, and consumption patterns, giving indicators for measures to alleviate severe financial hardship or impoverishment, such as those for healthcare (catastrophic health expenditure) (8). While continuous evaluation of the household expenditure patterns is relevant for policy planning and implementation, there seems to be insufficient data in this regard in Ghana.

Ascertaining the pattern of expenditure among this unique group does not only inform policy makers about heterogeneity in demand among older people, but gives an idea of how demand and costs are evolving in this population (9). A degree of ambiguity remains in the relationship between ageing populations and health care expenditure (10). The objective of this study is therefore, to explore the levels and patterns of household expenditures in a nationally representative sample of households of the elderly in Ghana, with a focus on determining direct medical costs within overall expenditures.

\section{Methods}

\section{Data collection}

Data was obtained from the 2014/15 World Health Organisation (WHO) Study on global AGEing and adult health (SAGE) Ghana Wave 2. This included a follow-up sample from Wave 1, that consisted of nationally representative cohorts of adults aged 50 years and older, and smaller comparative samples of people aged 18-49 years (younger adults). Further information on SAGE, with country-specific household-level and person-level analysis weights, was made available by WHO (11).

\section{Participants, sampling and variables}

Recruitment of participants and implementation of the study was coordinated by the SAGE Ghana Team. SAGE Ghana employed a stratified random sampling strategy with households as the final sampling units (12). More details about the sampling strategies are available elsewhere (13). The sociodemographic characteristics information collected included age, sex, educational level, financial assistance, marital status and health insurance. Participants also self-assessed their perception of health as being 'Very Good', 'Good', 'Moderate', 'Bad', or 'Very Bad'. Outcome variables were total household expenditures and total direct medical costs over the year preceeding the interview. For each participant, 
the overall consumption and health expenditures of their households were determined from sub-variables obtained by interviewing an identified household informant. The total household expenditure and direct medical costs were defined as the sum of obtained sub-variables listed in Table 1. The catastrophic health expenditure was also determined for participants. In this study, expenditure was defined as being catastrophic if a household's direct medical cost was greater than or equal to $40 \%$ of total expenditure of the household, after subsistence needs (food) have been met $(13,14)$.

\section{Data analysis}

Total direct medical costs and total household expenditures were estimated by summing the costs of the individual categories (Table 1). Variables which were ascertained for a 30-day period were multiplied by 12 to obtain estimates of annual costs. All estimated costs were converted into US\$ using an exchange rate of GHS 3.21 (the average exchange rate over the period this study was conducted).

All variables were analyzed using Stata 14 software (StataCorp. College Station, TX). SAGE wave 2 used adjusted weights due to the complex nature of the study design. In determining estimations, adjusting for the participants' weighting, stratification and clustering in a complex survey dataset was a key issue considered during data analysis. SAGE wave 2 adopted a multistage cluster survey design, and adjusted for the primary sampling units, stratification, and the sampling weights to reduce bias and to improve data analysis in all estimates.

Descriptive statistics were used to describe participant characteristics and mean values of cost estimates between groups compared. Proportions of participants with catastrophic health expenditure were reported, while Chi-square test was used to test association between categorical variables, at $95 \%$ confidence, assuming an alpha level of 0.05 .

Table 1: Description of input variables for the selected analytical outcomes 


\begin{tabular}{|c|c|c|}
\hline $\begin{array}{l}\text { ependent } \\
\text { ariable }\end{array}$ & Sub-variables & Description \\
\hline \multirow[t]{11}{*}{$\begin{array}{l}\text { irect } \\
\text { edical costs }\end{array}$} & Consultations & $\begin{array}{l}\text { Registration and consultation fees by doctors, nurses, or trained } \\
\text { midwives that did not require an overnight stay }\end{array}$ \\
\hline & $\begin{array}{lr}\text { Traditional } & \text { or } \\
\text { alternative } & \text { health } \\
\text { care } & \end{array}$ & Care by traditional or alternative healers \\
\hline & Investigations & Diagnostic and laboratory tests such as X-rays or blood tests \\
\hline & Medications & $\begin{array}{l}\text { Medications or drugs form prescription, non-prescription, traditional, } \\
\text { homeopathic practitioners }\end{array}$ \\
\hline & Dental & Oral and dental care \\
\hline & $\begin{array}{l}\text { Mandatory health } \\
\text { insurance }\end{array}$ & Mandatory health insurance premiums or pre-paid health plans \\
\hline & $\begin{array}{l}\text { Voluntary health } \\
\text { insurance } \\
\text { premiums }\end{array}$ & $\begin{array}{l}\text { Voluntary health insurance premiums (including, community health } \\
\text { insurance schemes }\end{array}$ \\
\hline & $\begin{array}{l}\text { Health-related } \\
\text { items }\end{array}$ & $\begin{array}{l}\text { Items such as prescription glasses, hearing aids, canes, prosthetic } \\
\text { devices }\end{array}$ \\
\hline & Overnight stays & Costs associated with overnight stays in a hospital or health facility \\
\hline & Care facility & Costs associated with long-term care facility \\
\hline & Others & Any other health care products or services that were not included above \\
\hline \multirow{9}{*}{$\begin{array}{l}\text { otal } \\
\text { susehold } \\
\text { xpenditure }\end{array}$} & Food & \\
\hline & $\begin{array}{l}\text { Housing } \\
\text { utilities }\end{array}$ & Rent, mortgage, electricity, heating/cooking fuel, water, telephone \\
\hline & Clothing & $\begin{array}{l}\text { Footwear, hats, shirts, pants, dresses, skirt, jackets, coat and other } \\
\text { personal items, such as soap, shampoo, cosmetics, shaving cream etc. }\end{array}$ \\
\hline & Transportation & Bus fares, cab/taxi fares, vehicle repair costs, petrol \\
\hline & $\begin{array}{l}\text { Recreation and } \\
\text { entertainment }\end{array}$ & Expenditure on entertainment and recreation \\
\hline & Education & $\begin{array}{l}\text { Costs of educational fees and supplies, such as tuition, course fees and } \\
\text { books }\end{array}$ \\
\hline & Durable goods & $\begin{array}{l}\text { Televisions, phones, bed sheets, towels, tools, furniture (tables, chairs, } \\
\text { beds) and appliances (refrigerators, washing machines }\end{array}$ \\
\hline & Taxes & $\begin{array}{l}\text { Property tax, vehicle tax, income tax, etc and non-health related } \\
\text { insurance (personal, vehicle, household, life) }\end{array}$ \\
\hline & Others & $\begin{array}{l}\text { All other goods and services aside health related ones which are not } \\
\text { listed above }\end{array}$ \\
\hline
\end{tabular}

\section{Results}

A final sample of 4,735 was used for analysis. This consisted of 1,948 (43.8\%) males and $2,787(56.2 \%)$ females ranging from 18 years to 110 years with a mean age of $57.6 \pm 16.7$. Nearly three-quarters $(75.5 \%)$ of the participants were 50 years or older (Table 2). Among the elderly however, $56.6 \%$ were males, $29.4 \%$ did not have health insurance, and $44.4 \%$ resided in rural communities.

Most of the participants with no formal education were older adults (49.9\%), compared to the $18.3 \%$ of the younger adult population $(P<0.001)$. Older adults were significantly more likely than younger adults to perceive their health to be either 'bad' or 'very bad' (OR=3.9, $\mathrm{P}<0.001)$. The marital status and health 
insurance coverage distribution among older adult age groups did not vary significantly. About $40.3 \%$ of households had received financial assistance within the past year (Figure 1). Of these, $32.2 \%$ were in the older adult group, compared to $8.0 \%$ of the younger adult population $(P=0.073)$. Also, $14.6 \%$ were in the rural areas, compared with $25.6 \%$ in the urban areas $(P<0.001)$.

The average annual household expenditures among adults in Ghana varied considerably among different subgroups (Table 2). The average household expenditure per annum for the entire population was US\$ $2,459 \pm 7,375$, with a US $\$ 246 \pm 1,922$ average annual household expenditure on health. Direct medical costs averagely accounted for $10 \%$ of the total household expenditures with levels different for younger and older adults ( $12.3 \%$ and $9.5 \%$ respectively). The proportions of the household expenditure components among older adults are shown in Figure 2. The prevalence of catastrophic health expenditure generally among older people in Ghana was 7.5\% (95\% Cl 6.0\% - 9.3\%). That of the entire population was however $7.8 \%(95 \% \mathrm{Cl} 6.5 \%$ to $9.4 \%)$. The household catastrophic health expenditure did not vary significantly across any of the variables studied.

Comparing the pattern of direct medical costs and total household expenditure across the sociodemographic characteristics, the average direct medical cost differed significantly across the health insurance status and the residential status. There was however no significant difference in the average total household expenditure across the different characteristics (Table 2). Out-of-pocket expenditures on transportation and traditional or alternative health therapies were higher among households of older adults, compared to the younger adult population. Though not significant, the inverse was observed for expenditurs on medications, dental care, food, housing and utilities (Table 3).

Table 2: Average household expenditure across participant sociodemographic characteristics, SAGE Ghana Wave 2. 


\begin{tabular}{|c|c|c|c|c|c|c|c|}
\hline riable & $\begin{array}{l}\text { Unweighted } \\
\text { Sample size }\end{array}$ & $\begin{array}{l}\text { Weighted } \\
\text { Proportion }\end{array}$ & $\begin{array}{l}\text { Average } \\
\text { Expenditure } \\
\text { (SD) }\end{array}$ & $\begin{array}{l}\mathrm{P}- \\
\text { value }\end{array}$ & $\begin{array}{l}\text { Average } \\
\text { Health } \\
\text { Expenditure } \\
\text { (SD) }\end{array}$ & $\begin{array}{l}\mathrm{P}- \\
\text { value }\end{array}$ & $\begin{array}{l}\text { Catastrophic } \\
\text { Expenditure } \\
(\%)\end{array}$ \\
\hline $\mathrm{x}$ & & & & 0.368 & & 0.247 & \\
\hline Male & 1,948 & 43.8 & $2,812 \pm 9,748$ & & $218 \pm 1,454$ & & 7.5 \\
\hline Female & 2,787 & 56.2 & $2,183 \pm 5,100$ & & $271 \pm 1,689$ & & 8.0 \\
\hline e categories & & & & 0.706 & & 0.516 & \\
\hline $18-49$ & 1,160 & 22.2 & $2,309 \pm 3,056$ & & $283 \pm 308$ & & 8.7 \\
\hline 50 and older & 3,575 & 77.8 & $2501 \pm 8307$ & & $237 \pm 1,829$ & & 7.5 \\
\hline lancial assistance & & & & 0.377 & & 0.645 & \\
\hline$=4,674)$ & 1,228 & 40.27 & $2,889 \pm 12,028$ & & $240 \pm 695$ & & 7.9 \\
\hline Yes & 3,446 & 59.73 & $2,181 \pm 4,813$ & & $252 \pm 1,825$ & & 7.7 \\
\hline No & & & & & & & \\
\hline rmal Education & & & & 0.120 & & 0.933 & \\
\hline None & 1,996 & 42.9 & $2,056 \pm 4,638$ & & $260 \pm 2,027$ & & 7.8 \\
\hline Less than primary & 653 & 12.0 & $1,913 \pm 3,024$ & & $201 \pm 2,354$ & & 5.8 \\
\hline Primary school & 701 & 12.8 & $2,320 \pm 3,593$ & & $273 \pm 316$ & & 10.1 \\
\hline Secondary school & 707 & 15.5 & $4,181 \pm 15,387$ & & $194 \pm 328$ & & 7.8 \\
\hline High school & 524 & 12.7 & $2,273 \pm 3,723$ & & $202 \pm 226$ & & 8.0 \\
\hline University & 147 & 4.0 & $2,838 \pm 13,051$ & & $520 \pm 693$ & & 5.1 \\
\hline Post graduate & 7 & 0.2 & $1,095 \pm 564$ & & $137 \pm 69$ & & 8.8 \\
\hline rception of health & & & & 0.253 & & 0.676 & \\
\hline Very good & 651 & & $2,259 \pm 1,939$ & & $222 \pm 869$ & & 9.8 \\
\hline Good & 2,541 & 5.7 & $2,045 \pm 2,449$ & & $224 \pm 338$ & & 7.9 \\
\hline Moderate & 1,114 & & $2,233 \pm 7,826$ & & $341 \pm 3,178$ & & 6.6 \\
\hline Bad & 329 & 59.0 & $8,474 \pm 22,429$ & & $191 \pm 198$ & & 13.8 \\
\hline Very bad & 61 & & $3,259 \pm 9,915$ & & $129 \pm 120$ & & 3.1 \\
\hline
\end{tabular}

5.0

2.7

\begin{tabular}{|c|c|c|c|c|c|c|c|}
\hline \multicolumn{4}{|l|}{ arital status } & \multicolumn{2}{|l|}{0.257} & \multicolumn{2}{|l|}{0.303} \\
\hline Married/Cohabiting & 2,693 & 51.1 & $2,863 \pm 10,868$ & & $276 \pm 1,965$ & & 8.5 \\
\hline Single & 2,042 & 48.9 & $2,037 \pm 2,449$ & & $218 \pm 1,246$ & & 7.0 \\
\hline :alth Insurance & & & & 0.051 & & $0.024^{*}$ & \\
\hline Yes & 3,449 & 68.4 & $2,791 \pm 8,460$ & & $279 \pm 1,837$ & & 7.5 \\
\hline None & 1,276 & 31.6 & $1,739 \pm 2,873$ & & $183 \pm 572$ & & 8.4 \\
\hline sidence & & & & 0.523 & & $0.049^{*}$ & \\
\hline Rural & 2,770 & 44.5 & $2,708 \pm 8,160$ & & $279 \pm 1,286$ & & 7.2 \\
\hline Urban & 1,965 & 55.5 & $2,259 \pm 6,100$ & & $183 \pm 1,952$ & & 8.2 \\
\hline tal & 4,735 & 100 & $2,459 \pm 7,375$ & - & $246 \pm 1,922$ & - & 7.8 \\
\hline
\end{tabular}

US\$1.00 equivalent to GHS3.21 (Bank of Ghana average monthly interbank exchange rate, December 2014)

Table 3: Pattern of household expenditure among adults in Ghana, SAGE Ghana Wave 2, 2015 (in US\$) 


\begin{tabular}{llll}
\hline Variable & 18 to 49 & $50+$ & p-value \\
\hline Traditional/alternative health care & $46 \pm 171$ & $79 \pm 248$ & 0.822 \\
\hline Medications & $155 \pm 219$ & $131 \pm 326$ & 0.810 \\
\hline Dental & $34 \pm 15$ & $33 \pm 10$ & 0.210 \\
\hline Food & $883 \pm 653$ & $854 \pm 796$ & 0.526 \\
\hline Housing and utilities & $200 \pm 260$ & $666 \pm 6,797$ & 0.307 \\
\hline Clothing & $104 \pm 122$ & $119 \pm 175$ & 0.220 \\
\hline Transportation & $139 \pm 273$ & $161 \pm 241$ & 0.093 \\
\hline
\end{tabular}

\section{Discussion}

This study set out to determine the pattern of household expenditure among older adults in Ghana, while ascertaining their direct medical costs. The results from this study comes as pertinent for several reasons, especially in a low-middle income country such as Ghana and similar countries in the subregion. Ghana has shown a gradual change in its demographic characteristics due to population ageing (16). The somewhat gradual pace provides valuable lead time for strategic planning and policy development to ensure systems are prepared for the coming changes. Estimates of household expenditure, such as those from this study, could therefore be used to inform policies, with regards to prioritization, health insurance, reimbursements, social services, housing, transportation and agriculture among older persons.

It is important to establish that though the pattern of household expenditure holds great predictive value in planning, it is affected by many individual preferences which may be difficult to account for (behavioural heterogeneity) (9). There are also assertions of age-associated health conditions which could increase the household expenditures among older adults.

This study found the average household expenditure among the study participants to be US\$2,459. These low estimates, though excluding taxes, are considered characteristic of low income countries which Ghana was, at the time of the study. Furthermore, the average direct medical cost, being US\$246, accounted for $10 \%$ of the average total expenditure. It has been suggested that at low income levels, spending diversity is low, as food and healthcare might be expected to dominate spending (9). In corroboration with this, food and healthcare took a proportionate $35 \%$ and $10 \%$ of the total household expenditure in this study. In comparison to these, average annual health expenditure was estimated to be US\$7,439 among older populations in Australia at about the time of this study (10). Also, in this study, $5 \%$ of household expenditure was accrued by medications, while $3 \%$ was spent on herbal/alternative medicines. This further substantiates the high prevalence of alternative/traditional medicine usage among older Ghanaian adults (17). Compared to younger adults, older adults spent more on transportation and traditional or alternative health therapies. While the elderly are likely to spend more on conveyance, especially for those with mobility related illnesses, the cultural context influences ageing and health practices. Traditional and alternative medicine use is inadmisible to the cultural setting of many people in sub-Saharan Africa, possibly accounting for its significant presence in the household expenditure of older adults in this study (18). 
The population characteristics of this study is similar to findings of Issahaku and Neysmith (2013), who also reported that a higher proportion of the elderly in West Africa is female, with many having little or no formal education, and found more in rural areas (19). Comparatively, Ogura and Jakovljevic (2018) also describe the elderly in higher income countries as being mostly female, poor, and living alone (3).

Aside being a LMIC, the pattern of expenditure among older Ghanaians generally differs from that of Japan $(20)$, UK $(9,21)$, and the USA (22), due to the entire prevailing social, political and cultural systems. For instance, health financing in Ghana is mainly publicly funded through the National Health Insurance scheme (NHIS), which, as of the commencement of this study in 2014, covered some 10.4 million Ghanaians, approximating $40 \%$ of the country's population (23). The fairly large coverage, which is free for adults aged 70-plus years, and the 'core poor' defined as the unemployed with no visible source of income, no fixed residence, and not living with someone employed and with a fixed residence (24), could significantly have contributed to the comparatively lower out-of-pocket expenditure on health in this study. Also, the $27 \%$ expenditure on household and utilities could be a manifestation of the deep-rooted housing crises in Ghana, which has seen several attempts at reforms over the past few decades (25). With rising cost of rent, cheaper alternatives and settlements, especially in rural areas could be the preference among older adults. The 17\% 'Other' category (Figure 1) could be a reflection of the heterogeneity of the study population. Included in this category are taxes, gifts, recreation, among others.

Safeguarding people from catastrophic payments, that is, financial hardship caused by health payments, has come to be a widely accepted index, and a desirable objective in health policy. This study found the prevalence of catastrophic health expenditure among older adults in Ghana to be $7.8 \%$, using a $40 \%$ threshold. The catastrophic household health expenditure was reported to be $1.6 \%$ from a survey in 1998 (8). As catastrophic health spending is generally thought to be rising, our figure comparatively relates to the $7 \%$ prevalence found in India (15). It was also reported to be $22.2 \%$ in Iran (26), 6-15\% in Burkina Faso (27), and $8-14 \%$ in Thailand (28). Nearly $40 \%$ of the households had obtained financial assistance, while many $(30 \%)$ had salaries being the major source of financing. A significant $34 \%$ of older population had to borrow money or sell their property to finance their expenditure. Nearly half of the older population had also not had any formal education, an observation which could inform the policy process and its implementation. These findings necessitates the need for a broader discussion on health financing, as the transition to a more aged society brings considerable financial challenges to any economy (3). Beyond the effective and more tailored implementation of the NHIS, some authors have suggested for the provision of basic income for persons aged 60 years and above (19), while free or subsidized transportation could be considered of the very elderly in the society.

This study is limited by the few variables explored. Also, being cross-sectional, this study provides only point estimates, for which care must be taken in the interpretation of its results. Recall bias, as in many costing studies could have influenced households' report of expenditures.

\section{Conclusion}


This study in many ways highlights the unmet need for social support for older Ghanaians. In providing estimates and pattern of the expenditure of this group, detailed planning could be incorporated into social interventions. Findings from this study could also be used in hypotheses generation for future studies to explore how the older population in Ghana is evolving.

\section{Abbreviations}

LMIC: Lower-Middle Income Countries; NHIS: National Health Insurance Scheme; WHO: World Health Organization; SAGE: Study on global AGEing and adult health; UHC: Universal Health Coverage

\section{Declarations}

\section{Authors' contributions}

AY, SH and PKB conceptualized and designed the study. PKB and SH were responsible for extraction of data. PKB, SH, NM, KP, ML and AY analyzed and interpreted the data. All authors drafted, read and approved the final manuscript.

\section{Ethical requirements}

SAGE was approved by the World Health Organization's Ethical Review Board (reference number RPC149) and the Ethical and Protocol Review Committee, College of Health Sciences, University of Ghana, Accra, Ghana. Written informed consent was obtained from all study participants.

\section{Consent for publication}

Not applicable

\section{Declaration of interests}

The authors declare that there are no conflicts of interest regarding the publication of this article

\section{References}

1. Mba CJ. Population ageing in Ghana: Research gaps and the way forward. J Aging Res. 2010;2010.

2. Kpessa-Whyte M. Aging and Demographic Transition in Ghana: State of the Elderly and Emerging Issues [Internet]. Vol. 58, Gerontologist. 2018 [cited 2020 Apr 21]. p. 403-8. Available from: https://www.ncbi.nlm.nih.gov/pubmed/29381779

3. Ogura S, Jakovljevic MM. Editorial: Global Population Aging - Health Care, Social and Economic Consequences. Front Public Heal [Internet]. 2018 Nov 20 [cited 2020 Jun 5];6(NOV):335. Available from: https://www.frontiersin.org/article/10.3389/fpubh.2018.00335/full

4. Zhang C, Rahman MS, Rahman MM, Yawson AE, Shibuya K. Trends and projections of universal health coverage indicators in Ghana, 1995-2030: A national and subnational study. Rockers P, editor. 
PLoS One [Internet]. 2019 May 22 [cited 2019 Dec 18];14(5):e0209126. Available from: http://dx.plos.org/10.1371/journal.pone.0209126

5. NATIONAL AGEING POLICY 'AGEING WITH SECURITY AND DIGNITY': Ministry of Gender, Child and Social Protection [Internet]. [cited 2019 Mar 29]. Available from:

http://mogcsp.gov.gh/index.php/mdocs-posts/national-ageing-policy-ageing-with-security-anddignity/

6. Nortey ST, Aryeetey GC, Aikins M, Amendah D, Nonvignon J. Economic burden of family caregiving for elderly population in southern Ghana: the case of a peri-urban district. Int $\mathrm{J}$ Equity Health [Internet]. 2017 Dec 14 [cited 2019 Mar 29];16(1):16. Available from: http://equityhealthj.biomedcentral.com/articles/10.1186/s12939-016-0511-9

7. World Health Organization. Ghana country assessment report on ageing and health. Ghana Ctry Assess Rep ageing Heal [Internet]. 2014 [cited 2020 Jan 17];1-44. Available from: https://apps.who.int/iris/bitstream/handle/10665/194271/9789241509312_eng.pdf?sequence=1

8. Xu K, Evans DB, Kadama P, Nabyonga J, Ogwal PO, Nabukhonzo P, et al. Understanding the impact of eliminating user fees: Utilization and catastrophic health expenditures in Uganda. Soc Sci Med. 2006 Feb;62(4):866-76.

9. Chai A, Rohde N, Silber J. Measuring the Diversity of Household Spending Patterns [Internet]. 2013 [cited 2019 Mar 22]. Available from: https://core.ac.uk/download/pdf/143877460.pdf

10. Harris A, Sharma A. Estimating the future health and aged care expenditure in Australia with changes in morbidity. Callander E, editor. PLoS One [Internet]. 2018 Aug 9 [cited 2019 Mar 22];13(8):e0201697. Available from: https://dx.plos.org/10.1371/journal.pone.0201697

11. Kowal P, Chatterji S, Naidoo N, Biritwum R, Fan W, Ridaura RL, et al. Data resource profile: The world health organization study on global ageing and adult health (SAGE). Int J Epidemiol. 2012 Dec;41(6):1639-49.

12. Fan W, Arokiasamy P, Lopez Ridaura R, Maximova South Africa T, Phaswanamafuya R. Response rates HH Response Rate \% HH Cooperation Rate \% IND Response Rate \% IND Cooperation Rate \% [Internet]. [cited 2019 Mar 22]. Available from: https://www.who.int/healthinfo/sage/SAGEWorkingPaper5_Wave1Sampling.pdf?ua=1

13. Naidoo N. SAGE Working Paper No. 5. WHO Study on global AGEing and adult health (SAGE) Waves 0 and 1 - Sampling information for China, Ghana, India, Mexico, Russia and South Africa., World Health Organisation. World Heal Organ. 2012;1-9.

14. Xu K, Evans DB, Kawabata K, Zeramdini R, Klavus J, Murray CJL. Household catastrophic health expenditure: A multicountry analysis. Lancet. 2003;362(9378):111-7.

15. Brinda EM, Kowal P, Attermann J, Enemark U. Health service use, out-of-pocket payments and catastrophic health expenditure among older people in India: The WHO study on global AGEing and adult health (SAGE). J Epidemiol Community Health. 2015;69(5):489-94.

16. Tawiah EO. Population ageing in Ghana:a profile and emerging issues. African Popul Stud [Internet]. 2011 Dec 30 [cited 2019 Apr 22];25(2). Available from: 
http://aps.journals.ac.za/pub/article/view/249

17. James PB, Wardle J, Steel A, Adams J. Traditional, complementary and alternative medicine use in Sub-Saharan Africa: a systematic review. BMJ Glob Heal [Internet]. 2018 Oct 31 [cited 2019 Apr 24];3(5):e000895. Available from: http://gh.bmj.com/lookup/doi/10.1136/bmjgh-2018-000895

18. James PB, Wardle J, Steel A, Adams J. Traditional, complementary and alternative medicine use in Sub-Saharan Africa: A systematic review. BMJ Glob Heal. 2018 Nov 1;3(5):e000895.

19. Issahaku PA, Neysmith S. Policy implications of population ageing in West Africa. Vol. 33, International Journal of Sociology and Social Policy. Emerald Group Publishing Limited; 2013. p. 186-202.

20. Harris A, Sharma A. Estimating the future health and aged care expenditure in Australia with changes in morbidity. Callander E, editor. PLoS One [Internet]. 2018 Aug 9 [cited 2019 Apr 23];13(8):e0201697. Available from: https://dx.plos.org/10.1371/journal.pone.0201697

21. Hazra NC, Rudisill C, Gulliford MC. Determinants of health care costs in the senior elderly: age, comorbidity, impairment, or proximity to death? Eur J Heal Econ [Internet]. 2018 Jul 30 [cited 2019 Apr 24];19(6):831-42. Available from: http://www.ncbi.nlm.nih.gov/pubmed/28856487

22. Kelley AS, McGarry K, Fahle S, Marshall SM, Du Q, Skinner JS. Out-of-pocket spending in the last five years of life. J Gen Intern Med [Internet]. 2013 Feb [cited 2019 Apr 24];28(2):304-9. Available from: http://www.ncbi.nlm.nih.gov/pubmed/22948931

23. Wang H, Otoo N, Dsane-Selby L. Ghana National Health Insurance Scheme: Improving Financial Sustainability Based on Expenditure Review [Internet]. The World Bank; 2017 [cited 2019 Apr 24]. Available from: http://elibrary.worldbank.org/doi/book/10.1596/978-1-4648-1117-3

24. Blanchet NJ, Fink G, Osei-Akoto I. The Effect of Ghana's National Health Insurance Scheme on Health Care Utilisation. Ghana Med J [Internet]. 2012 [cited 2019 Apr 24];46(2):76. Available from: https://www.ncbi.nlm.nih.gov/pmc/articles/PMC3426378/

25. Luginaah I, Arku G, Baiden P. Housing and health in Ghana: the psychosocial impacts of renting a home. Int J Environ Res Public Health [Internet]. 2010 [cited 2019 Apr 24];7(2):528-45. Available from: http://www.ncbi.nlm.nih.gov/pubmed/20616989

26. Daneshkohan A, Karami M, Najafi F, Karami Matin B. Household catastrophic health expenditure. Iran J Public Health. 2011;40(1):94-9.

27. Su TT, Kouyaté B, Flessa S. Catastrophic household expenditure for health care in a low-income society: A study from Nouna District, Burkina Faso. Bull World Health Organ. 2006 Jan;84(1):21-7.

28. Limwattananon S, Tangcharoensathien V, Prakongsai P. Catastrophic and poverty impacts of health payments: Results from national household surveys in Thailand. Bull World Health Organ. 2007 Aug;85(8):600-6.

\section{Figures}




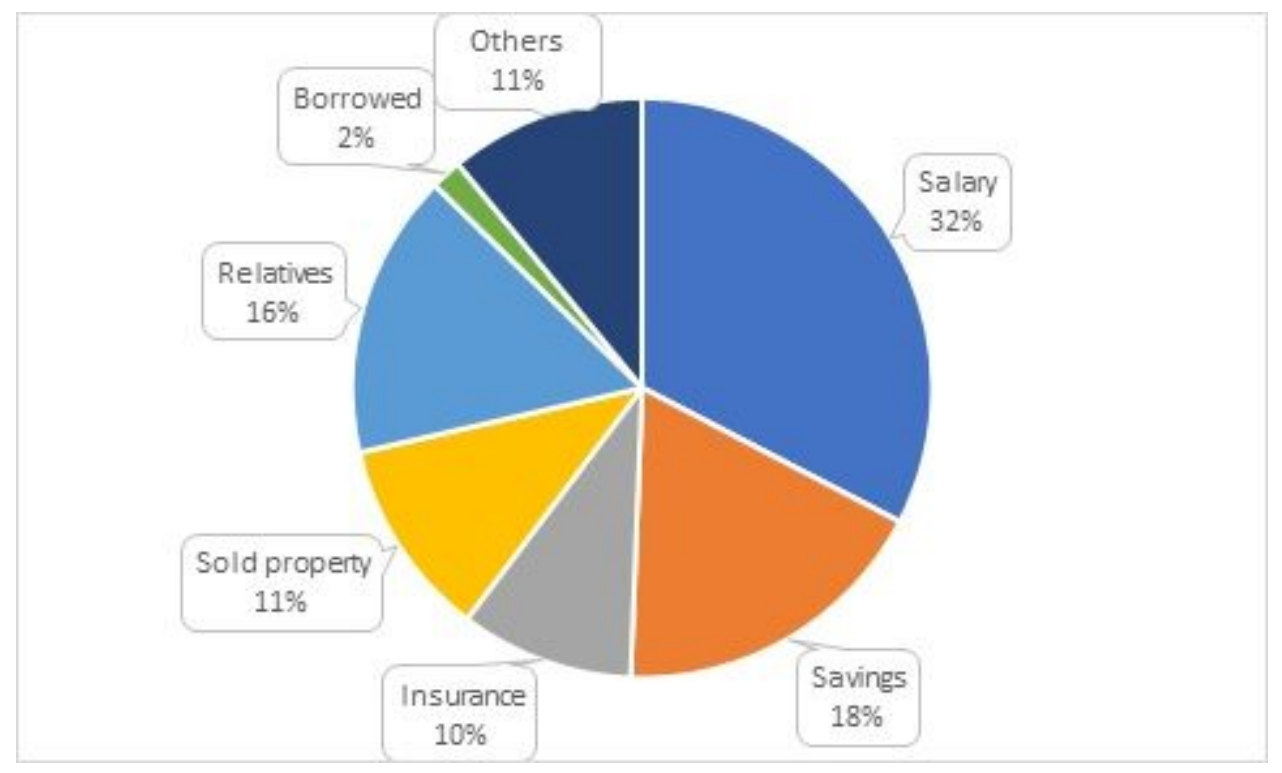

Figure 1

Sources of financing among the elderly in Ghana

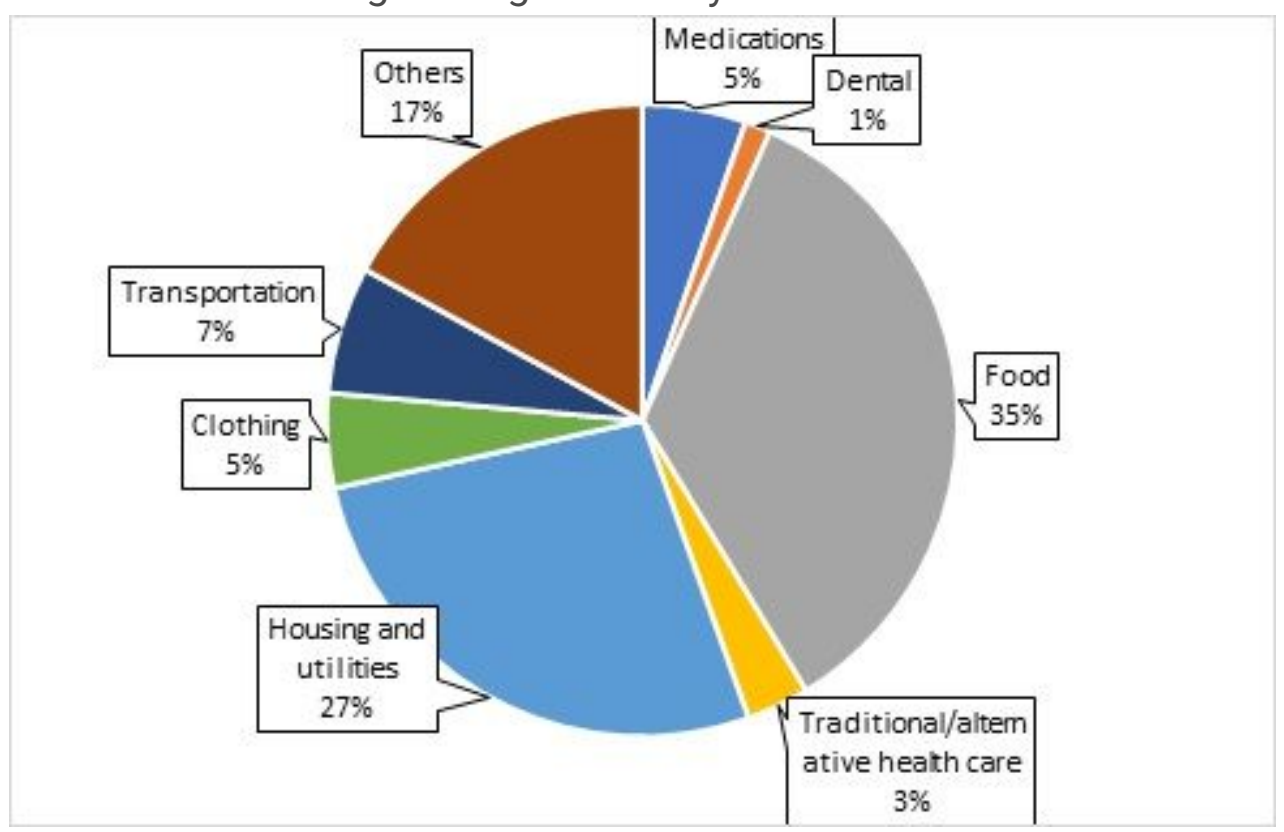

Figure 2

Proportions of cost areas among the elderly in Ghana 